\title{
Economic Selection of Generators for a Wind Farm
}

\author{
Omid Alavi*, Behzad Vatandoust \\ Department of Electrical Engineering, K.N. Toosi University of Technology, Tehran, Iran \\ *Corresponding author, e-mail: alavi.omid@mail.com
}

\begin{abstract}
The selection suitable generator for wind turbines will be done based on technical criteria and priorities of the project. In this paper, a method for determining the type of wind turbine generator with an example is explained. In the paper, for a $10 \mathrm{~kW}$ wind turbine, two generators have been proposed. The first case is a squirrel-cage asynchronous generator coupled to the turbine through the gearbox and directly connected to three phase output. Other PM generators that are directly coupled to the turbine and it is connected to the grid using the inverter. The results show that according to wind conditions, a $10 \mathrm{~kW}$ permanent magnet generator is more advantageous in terms of energy production.
\end{abstract}

Keywords: wind turbine, weibull, turbine generator, permanent magnet

\section{Introduction}

Selection of generator type for a wind farm depends on many parameters, such as access to the power grid, power generator, cost limit, turbine type, quality and quantity of wind and priorities such as efficiency, reliability and the maximum energy. Perhaps In most cases, all of the above are effective in choosing a generator. Usually, according to the priorities of each project, some of these factors are more important. For example, in Reference [1], Selection of turbine generator on the basis of economic aspects of generator stability was evaluated and an objective function based on the mean time to first failure and the mean time between two failures. In Reference [2] costs of a wind turbine are provided separately. Price in different parts of the unit (such as blades, gearbox, generator, etc.) based on the function of the diameter of the turbine is calculated. Therefore the cost function was obtained and Due to the energy taken to try to minimize it. In Reference [3] using the Monte Carlo method type of power generator units can be selected. Power Production capacity and production cost factor can be considered as optimization objectives. In Reference [4], using VSC, producing power generators in a wind farm is transferred to the DC bus and then used another converter for the transfer of power to a three-phase AC grid. Turbines always work at a speed that which have the most power to the grid. So it has not a speed governor. This variable speed is not an issue due to using the inverter. In Reference [5] layout optimization of the turbines in a wind farm is done. With the layout and the proper placement of the turbines overall efficiency has increased about $3 \%$. In Reference [6], optimized for PM synchronous generators with direct coupling to obtain the maximum power from the variable wind speed is done. In Reference [7], using the control of the blade pitch it has tried to obtain the maximum energy at low wind speeds. By controlling the pitch at high wind speed output power of the generator is limited to rated value. In Ref. [8], suitable turbine for a rural with $36500 \mathrm{kWh}$ annual consumption energy is selected from different turbine manufacturers. The basis of choice of $30 \mathrm{~kW}$ turbine for the power supply was the maximum efficiency during the year (the highest capacity factor) and climatic conditions of the region. In this paper, a method for selecting the $10 \mathrm{~kW}$ generator for wind turbine is provided. The basis of selection of obtaining maximum energy from the generator is respect to costs. For this purpose, the objective function is defined based on the cost-benefit consist of the cost of the generator and incurred equipment, the fixed cost of turbines and other equipment, the energy consumption during a year. To calculate the consumption energy, we used the Weibull curve for Sabzevar city. In this project, optimization carried out by two different generators:

1) Asynchronous generator with a direct connection (Direct Online) to the grid and coupled via the gearbox

2) Axial flux PM synchronous generator connected to the grid through an inverter and a direct coupling. 
In other words, the first is a fixed speed and the second is a variable speed type. In any case, considering the costs and the produced energy, optimized power generator is calculated and finally, two generators have been compared in terms of cost and benefit.

\section{Characteristics of Wind and Turbine}

In every region the distribution of wind follows Weibull function that this can be described by Equation (1):

$h(v)=\left(\frac{k}{c}\right)\left(\frac{v}{c}\right)^{k-1} e^{-\left(\frac{v}{c}\right)^{k}}$

$h$ : Weibull distribution function

$c:$ Scale factor $(\mathrm{m} / \mathrm{s})$

$k:$ Shape factor $(\mathrm{m} / \mathrm{s})$

$v:$ Wind speed $(\mathrm{m} / \mathrm{s})$

In this study, we used the standard deviation method to compute Weibull parameters.

To calculate the coefficient of cumulative and frequency distribution of Weibull, first it is necessary to calculate its first parameter that is $k$ shape.

Using this method, $k$ and $c$ are calculated respectively as [9]:

$k=\left(\frac{\sigma}{v}\right)^{-1.086}$

$c=\frac{v}{\Gamma\left(1+\frac{1}{k}\right)}$

$$
\Gamma(x)=\int_{0}^{\infty} \exp (-u) u^{x-1} d x
$$

In order to calculate the mean wind speed, $v$, and standard deviation of wind speed, $\sigma$, Equation (5), (6) can be used:

$$
\begin{aligned}
& v=\frac{1}{n} \sum_{i=1}^{n} v_{i} \\
& \sigma=\sqrt{\frac{1}{n-1} \sum_{i=1}^{n}\left(v_{i}-v\right)^{2}}
\end{aligned}
$$

In terms of Weibull distribution function, $v$ and $\sigma$ can be obtained as follows [9]:

$$
\begin{aligned}
& v=\int_{0}^{\infty} v f_{w}(v) d v=c \Gamma\left(1+\frac{1}{k}\right) \\
& \left.\sigma=\sqrt{c^{2}[} \Gamma(1+2 / k)-\Gamma(1+1 / k)^{2}\right]
\end{aligned}
$$

Figure 1 shows the Sabzevar Weibull diagram based on $c=7.29 \mathrm{~m} / \mathrm{s}$ and $k=1.73$ :

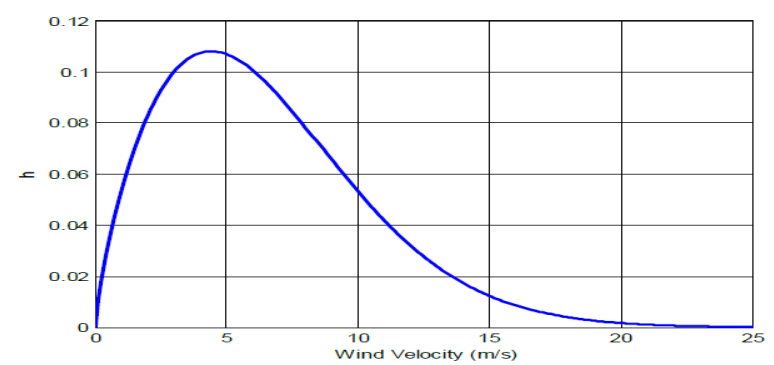

Figure 1. Weibull diagram in Sabzevar region 
If we want to calculate the probability that the wind speed is between $v_{0}$ and $v_{0}+\Delta v$, it is sufficient to take the integral of the function $\mathrm{h}$ between these two speeds.

To calculate the wind duration (in hours) between $v_{0}$ and $v_{0}+\Delta v$ throughout the year, we multiply the probability achieved in a total of 8760 hours of the year:

$$
\Delta t=8760 \times \int_{v_{0}}^{v_{0}+\Delta v} h(v) d v
$$

Table 1 shows the wind speed data in Sabzevar. Using these data, the parameters $k$ and $c$ are calculated for the Weibull diagram.

Table 1. The Speed and Wind Power Density in Sabzavar Region

\begin{tabular}{lllll}
\hline Month & $\mathrm{k}$ & $\mathrm{c}(\mathrm{m} / \mathrm{s})$ & Average power density $\left(\mathrm{W} / \mathrm{m}^{2}\right)$ & Most probable speed $(\mathrm{m} / \mathrm{s})$ \\
\hline January & 1.72 & 5.77 & 187.67 & 3.48 \\
February & 1.68 & 6.44 & 271.65 & 3.75 \\
March & 1.75 & 7.22 & 361.69 & 4.43 \\
April & 1.67 & 7.42 & 419.83 & 4.29 \\
May & 1.70 & 7.66 & 446.12 & 4.55 \\
June & 1.74 & 7.66 & 446.12 & 4.55 \\
July & 1.71 & 8.20 & 542.92 & 4.92 \\
August & 1.71 & 7.82 & 470.96 & 4.68 \\
September & 1.72 & 7.90 & 480.89 & 4.76 \\
October & 1.75 & 6.99 & 326.06 & 4.31 \\
November & 1.73 & 6.07 & 217.10 & 3.70 \\
December & 1.67 & 5.68 & 188.18 & 3.28 \\
Annual & 1.73 & 7.29 & 375.15 & 4.43 \\
\hline
\end{tabular}

The received power of the wind turbine can be calculated from Equation (10):

$P_{\text {mech }}=\frac{1}{2} C_{p} A \rho v^{3} \times 10^{-3}$

$P_{\text {mech }}:$ The received power from wind $(\mathrm{kW})$

$C_{p}$ : Turbine performance coefficient

$\rho:$ Bulk density of air $(1.1 \mathrm{~kg} / \mathrm{m} 3$ in $1000 \mathrm{~m})$

$A$ : Area swept by the turbine (m2)

$C_{p}$ is a quadratic function of ratio of the wind turbine speed in behind of the turbine to front of the turbine and ideally, the maximum value is 0.5 . Since the wind speed at the behind of the turbine depends on the geometry of the blades, $C_{p}$ is expressed based on the ratio of the linear velocity of the tip of the blade to the wind speed or the TSR:

$T S R=\lambda=\frac{r \omega}{v}$

$r$ : Radius of the turbine $(\mathrm{m})$

$\omega$ : Angular velocity of the turbine ( $\mathrm{rad} / \mathrm{s})$

If the turbine is equipped with a pitch angle control, $C_{p}$ will be a function of the angle of the blades $(\beta)$. Turbine studied in this paper is lacking the turbine pitch angle control. Figure 2 shows the variation of $C_{p}$ in terms of $\lambda$ :

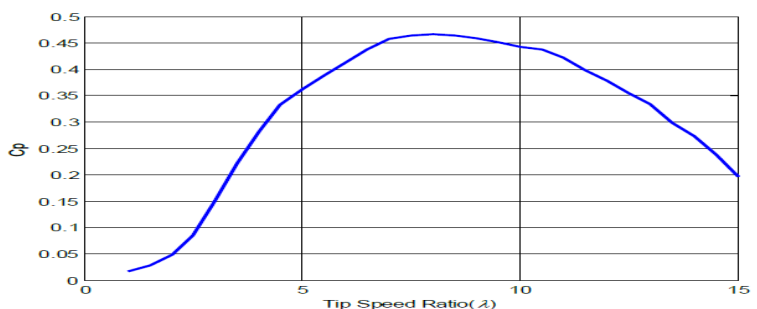

Figure 2. $C_{p}$ in terms of $\lambda$ 
This diagram is to be drawn by using the design software QBlade for the turbine and its characteristics are as follows:

Diameter turbine $=10 \mathrm{~m}$

Tower height $=11 \mathrm{~m}$

$v_{\text {cut }- \text { in }}=3 \mathrm{~m} / \mathrm{s}$

$v_{\text {cut }- \text { out }}=12 \mathrm{~m} / \mathrm{s}$

\section{Energy Calculation}

Machine efficiency is usually in nominal operating point. While efficiency is a curve that it is started with zero in non-load and with increasing engine load, increases to a peak (which may be the same as the nominal operating point), and then begins to decline. If we consider a constant value for efficiency from non-load to full load large errors may occur. On the other hand, the machine efficiency diagram is usually not available. For less errors, the machine losses divided into two parts: Constant losses $P_{\text {rot }}$ and Load dependent losses $P_{v \text { Loss }}$.

The following values show the different parts efficiency in the rated load:

$\eta_{P M}:$ PM generator efficiency at full load $=0.92$

$\eta_{\text {ind }}:$ Asynchronous generator efficiency at full load $=0.81$

$\eta_{g b}:$ Gearbox efficiency at full load $=0.85$

$\eta_{\text {inv }}:$ Inverter efficiency at full load $=0.96$

For asynchronous generator and gearbox, we will consider $70 \%$ of full load losses as constant losses and other losses as load dependent losses. About the PM generator, the mechanical losses are less, we assumed the share of constant losses is $30 \%$ and the share of load dependent losses is $70 \%$. In general, if is a share constant loss factor, we have:

$$
\begin{aligned}
& \eta=\frac{P_{\text {out }}}{P_{\text {in }}}=\frac{P_{\text {out }}}{P_{\text {out }}+P_{\text {loss }}} \\
& P_{\text {loss }}=\frac{1-\eta}{\eta} P_{\text {out }} \\
& P_{\text {rot }}=\alpha \frac{1-\eta}{\eta} P_{\text {out }}
\end{aligned}
$$

Machine efficiency without constant losses is as follows:

$$
\eta_{v}=\frac{P_{\text {out }}}{P_{\text {out }}+(1+\alpha) \frac{1-\eta}{\eta}\left(P_{\text {out }}\right)}=\frac{\eta}{\eta+(1+\alpha)(1-\eta)}
$$

The system can be analysed in three modes:

\subsection{The First Case}

Turbine is connected directly to a $10 \mathrm{~kW}$ PM synchronous generator and the output is connected to a $50 \mathrm{~Hz}$ grid with an inverter. Due to use of the inverter, wind turbine can operate at variable speed. The speed of the turbine can be in the range of 75rpm to 150rpm. From Equation (13) constant losses in this case are as follows:

$$
P_{\text {rot }(P M 1)}=0.3 \times \frac{1-\eta_{P M}}{\eta_{P M}} \times 10 \mathrm{~kW}=0.26 \mathrm{~kW}
$$

The efficiency of the generator and the inverter without constant losses can be calculated from Equation (14) as follows:

$$
\eta_{v(P M 1)}=\frac{\eta_{P M}}{\eta_{P M}+(1-\alpha)\left(1-\eta_{P M}\right)} \eta_{i n v}=0.905
$$




\subsection{The Second Case}

This case is similar with the first case with the exception that the synchronous generator power is $15 \mathrm{~kW}$ and it can be changed without any other characteristics changing.

$$
\begin{aligned}
& \eta_{v(P M 1)}=\eta_{v(P M 2)} \\
& P_{r o t(P M 2)}=0.3 \times \frac{1-\eta_{P M}}{\eta_{P M}} \times 15 \mathrm{~kW}=0.39 \mathrm{~kW}
\end{aligned}
$$

\subsection{The Third Case}

Turbine is coupled to a $10 \mathrm{~kW}$ four-pole asynchronous generator through a gearbox with a ratio of 1:20 and three phase generator output is connected directly to the $50 \mathrm{~Hz}$ grid. The speed of the turbine from non-load to full load varies between 750rpm to 78rpm. Constant losses are calculated as follows:

$$
\begin{aligned}
& P_{\text {rot }(\text { ind })}=0.7 \times \frac{1-\eta_{\text {ind }} \eta_{g b}}{\eta_{\text {ind }} \eta_{g b}} \times 10 \mathrm{~kW}=3.167 \mathrm{~kW} \\
& n_{v(\text { ind })}=\frac{\eta_{\text {ind }} \eta_{g b}}{\eta_{\text {ind }} \eta_{g b}+(1-\alpha)\left(1-\eta_{\text {ind }} \eta_{g b}\right)}=0.88
\end{aligned}
$$

$n_{v(i n d)}$ shows the efficiency of the machine and gearbox without constant losses.

To calculate the annual energy, performance of the wind turbine and generator will be examined separately at low and high wind speeds:

Low wind speed: In this case, the generator works at a lower power than its nominal power and producing power is a function of wind speed and $C_{p}$. However, in the case where the PM generator is used, with suitable control of the inverter connected to the generator, $C_{p}$ is a constant value equal to the maximum is 0.466 .

For $10 \mathrm{~kW}$ permanent magnet generator, the annual energy per $\mathrm{kWh}$ is calculated from Equation (9) and (10) at speeds between $3 \mathrm{~m} / \mathrm{s}$ and $8 \mathrm{~m} / \mathrm{s}$ as follows:

$$
\begin{aligned}
& W_{P M 1} \frac{\frac{8 m}{s}}{s}=\int_{t_{1}}^{t_{1}+\Delta t} P_{\text {out }} d t=\int_{t_{1}}^{t_{1}+\Delta t}\left(P_{\text {mech }}-P_{v \text { Loss }}-P_{\text {rot }(P M 1)} d t=\int_{t_{1}}^{t_{1}+\Delta t}\left(P_{\text {mech }}-P_{v \text { Loss }}\right) d t-\right. \\
& \int_{t_{1}}^{t_{1}+\Delta t} P_{\text {rot }(P M 1)} d t=\eta_{v(P M 1)} \int_{t_{1}}^{t_{1}+\Delta t} P_{\text {mech }} d t-\left.P_{\text {rot }(P M 1)} \Delta t\right|_{\frac{3 m}{s}} ^{\frac{8 m}{s}}= \\
& \frac{1}{2} \times \frac{8760}{1000} \times \eta_{v(P M 1)} C_{p} A \rho \int_{\frac{3 m}{s}}^{\frac{8 m}{s}} v^{3} h(v) d v-0.26 \times 8760 \times 0.4974=13888 \mathrm{kWh}
\end{aligned}
$$

$3 \mathrm{~m} / \mathrm{s}$ speed is selected based on (using Equation (10) and Figure 2), that turbine can produce power at least as $P_{r o t}$ and with increasing wind speed it can be injected power into the grid. In $8 \mathrm{~m} / \mathrm{s}$ speed producing power is equal to the nominal power of the generator and the turbine mechanical power output is equal to the output power with the total system losses.

$\left.\Delta t\right|_{3 \mathrm{~m} / \mathrm{s}} ^{8 \mathrm{~m} / \mathrm{s}}$ shows the duration of the wind speed between $3 \mathrm{~m} / \mathrm{s}$ to $8 \mathrm{~m} / \mathrm{s}$ and it can be calculated from Equation (9). This value is obtained at 4357 hours.

For $15 \mathrm{~kW}$ permanent magnet generator, the annual energy per $\mathrm{kWh}$ is calculated at speeds between $3 \mathrm{~m} / \mathrm{s}$ and $9.5 \mathrm{~m} / \mathrm{s}$ as follows:

$$
\begin{aligned}
& \left.W_{P M 2}\right|_{3 m / s} ^{9.5 m / s}=\int_{t_{1}}^{t_{1}+\Delta t} P_{\text {out }} d t=\frac{1}{2} \times \frac{8760}{1000} \times \eta_{v(P M 2)} C_{p} A \rho \int_{\frac{3 m}{s}}^{\frac{9.5 m}{s}} v^{3} h(v) d v-0.39 \times 8760 \times \\
& 0.6=23954 k W h
\end{aligned}
$$

Because the power of this generator is higher wind speed is considered $9.5 \mathrm{~m} / \mathrm{s}$. In this speed the mechanical power output of the turbine is equal to the nominal power of the generator and the system losses.

The energy calculation for asynchronous generator is a little different. The turbine speed is constant and with changing in the wind speed, TSR value is changing and according to 
Figure 2 causes changing of $C_{p}$. Therefore $C_{p}$ should be considered as a function of wind speed.

In $5.5 \mathrm{~m} / \mathrm{s}$ speed, turbine can produce power at least $P_{\text {rot }}$ and gearbox losses and if the wind speed is a bit more to be able to be injected power into the grid. In $11 \mathrm{~m} / \mathrm{s}$ speed, mechanical power output of the turbine is equal to the nominal power of the generator and the total system losses.

If the wind speed is compared with the previous case, we can see in the previous case, the wind turbine has produced $17 \mathrm{~kW}$ power with $9 \mathrm{~m} / \mathrm{s}$ speed, while in this case producing power is $14.5 \mathrm{~kW}$ in $11 \mathrm{~m} / \mathrm{s}$. The reason is that the permanent magnet generator using the inverter, possibility to change of the speed of the generator exists at maximum of $C_{p}$.

$$
\begin{aligned}
& \left.W_{\text {ind }}\right|_{5.5 m / s} ^{11 \mathrm{~m} / \mathrm{s}}=\int_{t_{1}}^{t_{1}+\Delta t} P_{\text {out }} d t=\eta_{v(\text { ind })} \int_{t_{1}}^{t_{1}+\Delta t} P_{\text {mech }} d t-\int_{t_{1}}^{t_{1}+\Delta t} P_{\text {rot (ind })} d t=\frac{1}{2} \times \frac{8760}{1000} \times \\
& \eta_{v(\text { ind })} A \rho \int_{\frac{5.5 m}{s}}^{\frac{11 m}{s}} C_{p}(\lambda) v^{3} h(v) d v-\left.P_{\text {rot }(\text { ind })} \Delta t\right|_{\frac{5.5 m}{s}} ^{\frac{11 m}{s}}=12764 k W h
\end{aligned}
$$

High wind speed: In this case, with the controlled removal of the wind turbine from the wind direction (Furling), power from the wind is reduced and the output power of the generator is not exceeded from nominal value. In this case, the output power of the generator is equal to the nominal power. For $10 \mathrm{~kW}$ permanent magnet generator we have:

$$
\left.W_{P M 1}\right|_{8 m / s} ^{12 m / s}=\left.P_{\text {out }} \Delta t\right|_{\frac{8 m}{s}} ^{\frac{12 m}{s}}=\eta_{\text {inv }} \times 10 \mathrm{~kW} \times 8760 \times \int_{8 \mathrm{~m} / \mathrm{s}}^{12 \mathrm{~s}} h(v) d v=18112 \mathrm{kWh}
$$

$\Delta t$ shows the duration of the wind speed for the mentioned speeds during the year.

For $15 \mathrm{~kW}$ permanent magnet generator we have:

$$
\begin{aligned}
& W_{P M 2} \frac{12 m}{\frac{9.5 m}{s}}=\left.P_{\text {out }} \Delta t\right|_{\frac{9.5 m}{s}} ^{\frac{12 m}{s}}=\eta_{\text {inv }} \times 15 \mathrm{~kW} \times 8760 \times \int_{\frac{9.5 m}{s}}^{\frac{12 m}{s}} h(v) d v \\
= & 14145 \mathrm{kWh}
\end{aligned}
$$

For asynchronous generator we have:

$$
\left.W_{\text {ind }}\right|_{11 \mathrm{~m} / \mathrm{s}} ^{12 \mathrm{~m} / \mathrm{s}}=\left.P_{\text {out }} \Delta t\right|_{11 \mathrm{~m} / \mathrm{s}} ^{12 \mathrm{~m}}=10 \mathrm{~kW} \times 8760 \times \int_{11 \mathrm{~m} / \mathrm{s}}^{12 \mathrm{~m} / \mathrm{s}} h(v) d v=3218 \mathrm{kWh}
$$

All of the above integrals are numerically calculated using MATLAB software.

The total annual energy delivered to the grid is as follows:

10kW PM generator:

$$
W_{P M 1}=\left.W_{P M 1}\right|_{3 m / s} ^{8 m / s}+\left.W_{P M 1}\right|_{8 m / s} ^{12 m / s}=13888+18112=32000 k W h
$$

15kW PM generator:

$$
W_{P M 2}=\left.W_{P M 2}\right|_{3 m / s} ^{9.5 m / s}+\left.W_{P M 2}\right|_{9.5 m / s} ^{12 m / s}=23954+14145=38099 k W h
$$

$10 \mathrm{~kW}$ asynchronous generator:

$$
W_{P M 1}=\left.W_{i n d}\right|_{5.5 \mathrm{~m} / \mathrm{s}} ^{11 \mathrm{~m} / \mathrm{s}}+\left.W_{\text {ind }}\right|_{11 \mathrm{~m} / \mathrm{s}} ^{12 \mathrm{~m} / \mathrm{s}}=12764+3218=15982 \mathrm{kWh}
$$

\section{Compare the Cost and Value of Produced Energy Generators}

Table 2 shows the costs and Table 3 shows the value of the energy produced in one year. Any one of the generators are not effective. The energy production of this type is economically for more than 45 penny per kilowatt-hour. In any case, in this paper, the advantages of each generator studied in comparison with other types. 
Table 2. Approximate cost in various parts of the wind turbine

\begin{tabular}{lll}
\hline & Estimated Costs & \\
Asynchronous (\$) & Permanent Magnet (\$) & \\
\hline 4800 & 4800 & Blades \\
760 & 5200 & $10 \mathrm{~kW}$ Generator \\
& 8000 & $15 \mathrm{~kW}$ Generator \\
1480 & 1480 & Tower \\
600 & 600 & Panel \\
-- & 4400 & $10 \mathrm{~kW}$ Inverter \\
& 6800 & $15 \mathrm{~kW}$ Inverter \\
400 & 400 & Measurement and control equipments \\
60 & 60 & Cable \\
-- & 1000 & Charging Control \\
520 & & Gearbox \\
800 & 800 & Foundation \\
800 & 800 & Installation costs \\
10220 & 19540 & Total Cost 10kW \\
& 24754 & Total Cost 15kW \\
\hline
\end{tabular}

Table 3. Energy production cost in a year (13.34 p/kWh [10])

\begin{tabular}{lll}
\hline Type of generator & Energy production in a year $(\mathrm{kWh})$ & Energy value in a year (penny) \\
\hline PM 10kW & 32000 & 426880 \\
PM 15kW & 38099 & 508241 \\
Asynchronous & 15982 & 213200 \\
\hline
\end{tabular}

The cost of building of asynchronous is about $52 \%$ the cost of building of permanent magnet $(10 \mathrm{~kW})$. While the energy produced is about $50 \%$ of the permanent magnet. Although the difference is not too much.

From the continuity of energy production, asynchronous generator is started producing power from the $5.5 \mathrm{~m} / \mathrm{s}$ speed. In the case, permanent magnet generator can be produced power for $3 \mathrm{~m} / \mathrm{s}$ speed. This means that the asynchronous generator is stopped in most situations. Due to the asynchronous generator is operating at constant speed, all the changes of wind power appear as a tension in the blades and the structure that cause reduce the life of the structure the turbine. Therefore, in this respect, $10 \mathrm{~kW}$ permanent magnet generator is a better choice.

About $15 \mathrm{~kW}$ permanent magnet wind turbine, cost of building of this type is about $27 \%$ more than $10 \mathrm{~kW}$ type. While produced energy is only $19 \%$ higher, which indicates the advantage of $10 \mathrm{~kW}$ type.

However, it is important to note that these results are true only with a given Weibull curve in Figure 1. If the turbine installed in a region with the higher average wind speed, asynchronous generator would be more advantageous than $10 \mathrm{~kW}$ permanent magnet type. However, in this case of $15 \mathrm{~kW}$ can also be a suitable option.

\section{Conclusion}

Selecting the type of wind turbine should be done in each region. The results show that according to wind conditions, a $10 \mathrm{~kW}$ permanent magnet generator is more advantageous in terms of energy production. Also this type of generator has the inherent advantages such as less tension in turbine and structures, greater coherence in injection power into the grid. It should be considered the energy advantage is not perennial and in a region with higher average wind speed, asynchronous generator is more advantageous due to lower initial cost.

\section{References}

[1] Ming Z, Sikaer A, Weiting G, Chen L. Economic Analysis of the Stability in the Wind Turbine Selection. Asia Pacific Power and Energy Engineering Conference. 2010: 1-4.

[2] Xing-jia Y, Zuo-xia X, Lei C, Hong-xia S. Analysis of 1MW Variable Speed Wind Turbine Parameter Optimal Design Based on Cost Modeling Method. IEEE Conference on Industrial Electronics and Applications. 2007; 15: 817-821. 
[3] Yichun W, Ming D. Optimal choice of wind turbine generator based on Monte-Carlo method. International Conference on Electric Utility Deregulation and Restructuring and Power Technologies. 2008; 3: 2487-2491.

[4] Lu W, Ooi BT. Multi-terminal LVDC system for optimal acquisition of power in wind-farm using induction generators. Power Electronics Specialists IEEE Annual Conference. 2001; 32: 210-215.

[5] Wang F, Liu D, Zeng L. Modeling and simulation of optimal wind turbine configurations in wind farms. IEEE World Non-Grid-Connected Wind Power and Energy Conference. 2009: 1-5.

[6] Li H, Chen Z. Optimal direct-drive permanent magnet wind generator systems for different rated wind speeds. European Conference on Power Electronics and Applications. 2007: 1-10.

[7] Muljadi E, Butterfield CP. Pitch-Controlled Variable-Speed Wind Turbine Generation. IEEE Transactions on Industry Applications. 2001; 37: 240-246.

[8] Prasad RD, Bansal RC, Sauturaga M. Wind Energy Analysis for Vadravadra Site in Fiji Islands: A Case Study. IEEE Transactions on Energy Conversion. 2009; 24: 750-757.

[9] Fazelpour F, Soltani N, Rosen M. Wind resource assessment and wind power potential for the city of Ardabil, Iran. International Journal of Energy and Environmental Engineering. 2014: 1-8.

[10] http://www.wind-power-program.com/turbine_economics.htm. (accessed 27.03.15). 